\title{
THE INFLUENCE OF L1 (TAMIL LANGUAGE) IN THE WRITING OF L2 (ENGLISH)
}

\author{
Mahendran Maniam ${ }^{1 *}$, Samikkanu Jabamoney Samuel ${ }^{1}$, Suwarsih Madya ${ }^{2}$, Aladdin Assaiqeli ${ }^{1}$, \\ Department of Modern Languages, Faculty of Languages and Communications, Universiti Pendidikan Sultan Idris, 35900, Tanjung \\ Malim, Perak, Malaysia ${ }^{1}$ \\ The Department of English Language Education, Faculty of Languages and Arts, Yogyakarta State University, Indonesia ${ }^{2}$ \\ *Corresponding email: mahendran@fbk.upsi.edu.my
}

\begin{abstract}
This study focuses on the interference of L1 grammatical rules in the writing of L2 with specific reference to the interference of Tamil (L1) in English (L2). Though many research have been done in mother tongue interference, very few research have been conducted in terms of Tamil versus English. This study seeks to find out the components of the L1 (Tamil language) grammar that the students of Tamil schools use interchangeably in their daily writing of L2, namely English. This study will follow a mixture of qualitative and quantitative survey research design, the purpose of which is to find out the influence of mother tongue linguistic items in the writing of English (L2), among the standard 4 students of a selected school. The findings of the study clearly indicated that mother tongue and the national language interfered (negative transfer) in the writing of L2 among Tamil school students. Apart from the interference of $\mathrm{L} 1$, the research also found that there is a heavy influence of the national language (Malay) in the writing of students' L2.
\end{abstract}

Keywords: interference, mother tongue, positive transfer, negative transfer, second language acquisition

\section{Introduction}

The main focus of this study is on the effect of mother tongue grammatical rules in the writing of L2. In this study's context, the focus is specifically on the interference of Tamil grammatical rules in the writing of English. Furthermore, this study is to find out the components of the L1 grammar and the national language that are used by Tamil school students interchangeably in their daily writing of L2 English. In addition, it seeks further to find out the dominant grammatical components which dominate the inter-language grammar.

\subsection{A Brief History and Comparison of the Tamil Language and English Language}

Besides the Tamil language, the Tamil school students of Tamil-speaking community in Malaysia are required to learn and achieve a good proficiency level of two languages which are English and Bahasa Melayu.

Since Tamil language is the mother tongue, prominence is given to it in Tamil schools. Furthermore, Bahasa Melayu is the National
Language in Malaysia and attention is given to it in Tamil schools, also the attention is directed to English language as a second language in Malaysia. In the case of English language, English was formally introduced to Tamil school students when they were in standard 3. Nowadays, this practice is no longer in action since 2003, and the new practice introduces English to Tamil school students from year 1 for only an hour a week.

Based on the requirement of The Curriculum Specification for English Year 5 Sekolah Jenis Kebangsaan (vernacular school) regarding writing skills in the Year 5, the Tamil school students should be able to write simple paragraphs consisting of several sentences as a demonstration of acquiring the mechanics of writing. In that sense, teachers should make sure that students write in response to a variety of stimuli including personal experiences, stories, and classroom activities. To that end, students should be encouraged to write independently by their teachers. However, when the students are unable to write independently, the teachers gradually need to set guided writing 
exercises relaxing the amount of control as students show greater confidence.

\section{Statement of the Problem}

English Language teaching and learning in Tamil schools has been the talk of the teaching fraternity of late. There have been many debates on the performance of students in all types of schools in Malaysia but the problems in Tamil schools have not been addressed adequately. The main reasons for the failure of learning the language has to be studied thoroughly. Areas like cross - linguistics and teaching methodologies have to be given deep and special attention. Since students of Tamil schools have to study more than two languages in their vernacular schools, the chances of other tongue and national languages' interference occurring in the learning is highly likely to take place. Therefore a thorough study in this area is significant. This study is hoped to address inter languages issues in Tamil schools in Malaysia.

\section{Significance of the Study}

In Malaysia, there is a mutual agreement among all Malaysians on the need to improve the standard of English language. As a result, efforts are being made to boost English language learning and teaching in schools. Additionally, L2 learning provides valuable insights into teaching that will help teachers, no matter what their methodological slant. Therefore, this inter-language study seeks to find out the components of the L1 grammar that are used by Tamil school students interchangeably in their daily writing of L2, which is English. In addition, it seeks to find out the dominant grammatical components which dominate the inter-language grammar. Doing so, it is expected that this study further deepens the understanding about the theoretical debate regarding the influence of inter-language grammar.

This current study will be significant for Tamil school teachers of English. By understanding the influence of L1 knowledge in the writing of L2, Tamil school teachers will be able to adjust their approach in correcting grammatical errors accordingly. In the same manner, this study will allow curriculum planners to adapt the curriculum accordingly by providing them with a complete picture of the L2 teaching scenario in Tamil schools.

\section{Research Questions}

This study was designed to answer the following four research questions:

1. What are the linguistic items that have been transferred from L1 to L2?

2. Which linguistic items have been transferred positively?

3. Which linguistic items have been transferred negatively?

4. What are the other influence apart from the L1 influence (if any)?

\section{Objective of the Study}

The main objectives of this inter-language study are as follows:

First, to find out the components of the L1 grammar that are used by Tamil school students interchangeably in their daily writing of L2, English.

Second, to find out the dominant grammatical components which dominates the inter-language grammar.

\section{Literature Review}

It is expected that this study further deepen the understanding about the theoretical debate regarding the influence of inter-language grammar. For L2 teaching/learning, the identified interference emerged from this study findings will be used by the L2 teachers to help the students to learn L2, better without the cross linguistic problems. According to interference is a transfer whereby first language impact is imposed on the acquisition of a secondary language. He has stated in his argument that transfers can be controlled through student perceptions on what can be transferred and as they develop their mastery in secondary language learning. In learning the new language, students build their own set of rules using their first language knowledge but only when they believe it will help them in the learning or when 
they become advance enough in the second language. Ellis (1997) says it is important distinguish between mistakes and errors.

Alkhateeb (2018) investigated the transfer relationship between first language (L1) (Arabic) proficiency and second language (L2) (English) performance in writing skills of a Saudi bilingual graduate student. Regardless of the huge linguistic distinction between the English language and Arabic language, it is presumed that Arabic and English writing skills positively, negatively, and neutrally transferred in a dynamic relationship. The researcher has conducted observations and interviews with Fatimah, the participant of this study, and analyzed her texts in both languages to illustrate how dynamic relationships between L1 and L2 in the composition skills is and what the effects of language transfer in the composition skills between L1 and L2 are. The results demonstrate effects of L2 on L1 as the following; first, a reverse or backward transfer implemented in three ways; positive, negative, and neutral transfer. Second, they indicate that there is a dynamic relationship between second language performance and first language proficiency in composition particularly. It is hoped that this knowledge will assist students in being aware of the effects of L2 on L1 specifically in composition and taking the advantages to accelerate the rate of language learning.

Murakami and Alexopoulou (2016) revisited morpheme studies to evaluate the long-standing claim for a universal order of acquisition. The researchers investigated the L2 acquisition order of six English grammatical morphemes by learners from seven L1 groups across five proficiency levels. Data were drawn from approximately 10,000 written exam scripts from the Cambridge Learner Corpus. The study established clear L1 influence on the absolute accuracy of morphemes and their acquisition order, therefore challenging the widely held view that there is a universal order of acquisition of L2 morphemes. Moreover, the study revealed that L1 influence is morpheme specific, with morphemes encoding languagespecific concepts most vulnerable to L1 influence.
Erdocia and Laka (2018) tested whether L1Spanish speakers of L2-Basque process subjectverb-object (SVO) and object-verb-subject (OVS) non-canonical word order sentences of Basque in the same way as Basque native speakers. Crucially, while OVS orders are non-canonical in both Spanish and Basque, SVO is non-canonical in Basque but is the canonical word order in Spanish. The results showed that the characteristics of L1 affect the processing of the L2 even at highly proficient and early-acquired bilingual populations. The findings indicated that L2-Basque speakers rely in their L1-Spanish when processing SVO-OVS word order sentences.

There is a controversy that needs to be taken into account - the extent of the disorder that is a negative transfer that covers the various offenses committed by anyone who is learning a new language. There are several researchers proposed that highly errors are consistent with the development of a student-rule system called interlanguage speech caused by wrong conclusions of the target language compared than harassment from the first language.

In another recent research, Dewi et al. (2019) examined L1 influence on L2 spelling acquisition. The study aimed to investigate the influence of Brebes Javanese phonological and orthographic system towards students' spelling of English words. The research questions were (1) how do Brebes Javanese L1 learners of English spell English words which contain phonemes that do not exist in Brebes Javanese dialect? And (2) what are the spelling errors of Brebes Javanese L1 learners of English when spelling English words containing non-existent phonemes in Brebes Javanese dialect? The subjects were 12 students of grade 12 in Brebes, Central Java, Indonesia. Tshe data were gathered from the students' spelling in reading aloud an English text twice and some isolated words once, while other supporting data were collected through questionnaires, recordings, observations, and interviews. The main result revealed that the students tend to misspell the English words which contain non-existent phoneme, and they replace with similar sounds in 
their L1. In addition, majority of students misspelled the sounds: /v/ to /f/; /I/ to /i// /æ/ to /e/; $/ \mathrm{d} 3 /$ to $/ \mathrm{k} /, / \mathrm{d} /, / \mathrm{t} /, / \mathrm{g} / ; / \mathrm{a} /$ to $/ \mathrm{N} / ; / \mathrm{t} /$ to $/ \mathrm{t} / ; / \mathrm{J} /$ to $/ \mathrm{J} /$.

\section{Research Design}

A mixture of qualitative and quantitative survey research design was adopted in this study. The main purpose of which is to investigate the grammatical influence of mother tongue, Tamil language, on the writing of L2 and whether the influence, if any, is a positive transfer or a negative one.

\section{Sampling}

Sampling is defined as the technique or process of selecting a suitable representative part of a population for the purpose of determining characteristics or parameters of the whole population. The sampling method used to identify the samples for this research was convenient sampling. According to Lavrakas, convenient sampling is a type of non-probability sampling in which participants are chosen because simply they are 'convenient' sources of data for researcher. Year 4 students are the samples used in this research simply because the class is being taught by the researcher and it would be easier and convenient to collect data. There are 30 pupils in the Year 4 ESL classroom and all the pupils were chosen as the sample for this study. The school is situated in urban area with mixed socioeconomic background. All the pupils are of Indian origin and so, their first language would be Tamil language and their second language is English. On the other hand, the national language of Malaysia is Bahasa Melayu.

\section{Instruments}

Analysis of pupils' writings

Interview Questions (Teachers of L1 \& L2 and sample)

\section{Data Analysis}

The researcher analyzed the data collected from the two instruments. The data was collected from the document analysis and interviews. The researcher employed various techniques to analyze the data which is mentioned below.

\section{Interviews}

It is believe that "Interviewing is an important way for a researcher to check the accuracy of-to verify or refute- the impressions he or she has gained through observation. Fetterman, in fact, describes interviewing as the most important data collection technique a qualitative researcher possesses. We interview people to find out from them things that we cannot directly observe."

Three semi-structured interviews were conducted in this study with the selected participants in order to identify the development of fluency in students, also to identify how students improve access to their linguistic system over practice and time. In the same manner, both respective school teachers of L1 and L2 were interviewed in order to identify the types of grammatical errors that the pupils make in their daily writing. In addition, another aim of the interview was to find out the influence of the students' mother tongue L1 on their writing in English.

\subsection{Interview 1}

\section{Analysis of Sample's Essay}

The L2 teacher of the respondents read and analyzed the written exercises to identify the errors made by the samples, in their writing activities. The source of the written work was from the students' classroom essay writing activity, (worksheets given by their L 2 teacher). The results of the errors made were tabulated and categorized according to linguistic items. The sample's worksheets used in the classroom was sure to provide valuable information (provided the written work was not directly copied from the teacher's notes) pertaining to students' L1 interference in the L2 writing. Therefore, the researcher only analyzed written materials that were done by the students without the L2 teacher's help or guide. The essays were thoroughly analyzed in order to obtain the required valuable information. The tabulated linguistic items were later compared and corroborated to 
substantiate the theoretical arguments in the field of language transfer

All the 35 essays written by the respondents were marked by a qualified L2 teacher. The errors found were compartmentalized into four main sections: Missing Capital Letters, The Use of Tamil Word
Order, Missing Punctuation and The Use of Malay Spellings.

\section{Types of Linguistic Errors}

Data from the Figure 1 clearly shows that there were a total of 188 errors, MUCL (73), MS (49), MP (35) and the use of TLS (31).

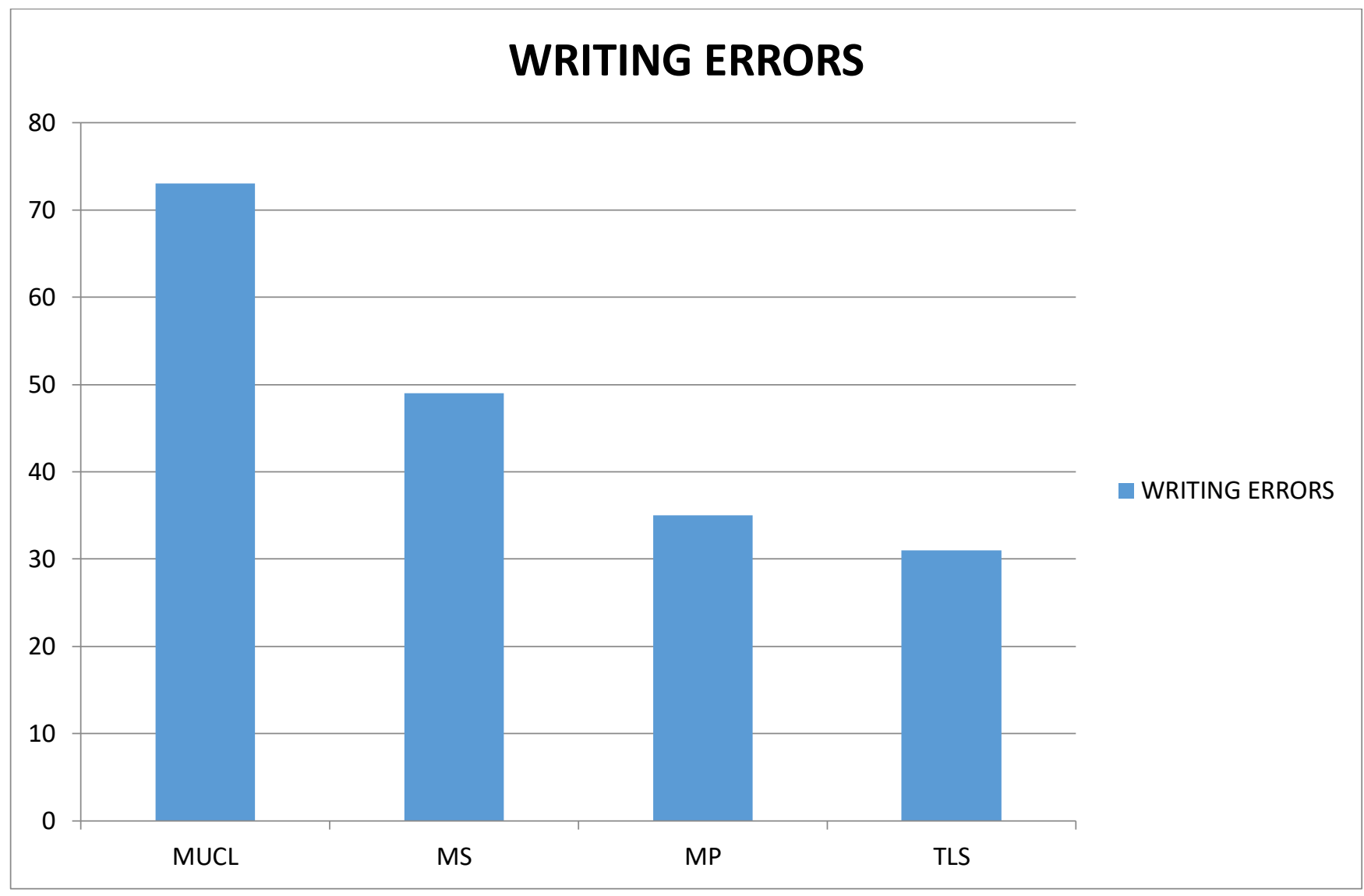

Figure 1. Types of Linguistic Errors

Figures shown in the bar chart was also supported by data retrieved from the interview transcription. For example in 'Missing Upper Case' category there were 73 sentences with such errors. Only 2 students or $5.7 \%$ of the respondents wrote the whole essay without missing the required capital letter for Proper Noun.

\section{Student 1}

'When I write in English, I always forget that we have upper case letters in English because there is no capital letter in Tamil writings.'

\section{Student 2}

'Sometimes I forget I am writing in English, I always miss the capital letters...'

\section{Missing Capital Letters}

Out of the 35 essays marked, there were two $(6 \%)$ without any errors in MUCL, 12 (34\%) with one error, nine $(25 \%)$ with two errors, seven $(20 \%)$ with three errors, four (12\%) with four errors and one $(3 \%)$ with six errors. 


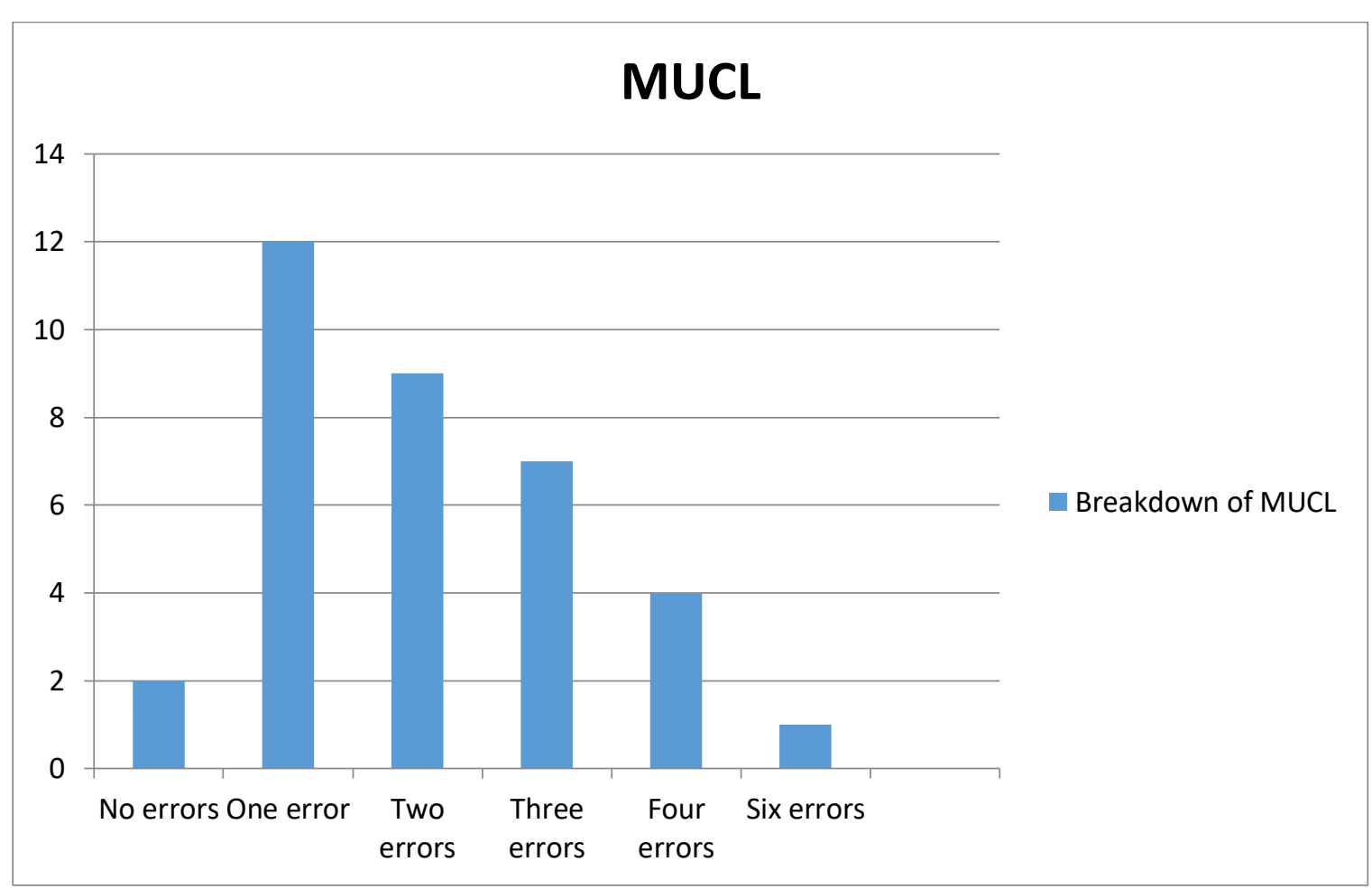

Figure 2. Failures to Use Capital Letters

\subsection{Capitalization}

As the Tamil language does not have any lower and upper case in the Tamil alphabet, Tamil school students writing English, are always influenced by this phenomena. The sentences analyzed by the researcher revealed that all the sentences in the students' writing materials and almost half of the sample's essays have missing capital letters. They failed to start the sentences with a capital letter. It was as if the capital letter did not exist in the language. The researcher listed the number of errors in this grammatical item and tabulated them. From the analysis we can observe that $94 \%$ of the students did not use upper case. The 35 students made a total of 73 errors in this grammar component. Even the word ' $I$ ' is written as ' $i$ ' by many students. This statistics is also supported by the literature of the Tamil language pattern and transcripts of interviews conducted with the students. The students agreed that Tamil is not an easy subject compared to English. All the English sentences written by the students were carefully analyzed and the researcher found that most of the sentences constructed by the students did not begin with a capital letter. Neither did they wrote the first person pronoun, 'I' in capital. Most of the proper nouns too were not capitalized (e.g. castel field Tamil school) Their writing (mostly from the intermediate class) seemed to be as if capitalization did exist in the English language.

\subsection{Punctuation}

There are 14 punctuation marks that are commonly used in English grammar. They are the period, question mark, exclamation mark, comma, semicolon, colon, dash, hyphen, parentheses, brackets, braces, apostrophe, quotation marks and ellipsis. In this research, out of the 35 students, 29 $(83 \%)$ of the students did not use proper punctuation like full stop, comma, question mark, colon, semi colon and apostrophes. As such punctuation marks are rarely used in their L1, the respondents were influenced with the same pattern in their L2 writings. One (3\%) respondent made four such mistake, four respondents (12\%) made two mistakes each in their essay writing and 23 respondents (69\%) made one mistake. At the same time six respondents (18\%) did not make any mistakes in punctuation in their writings. 


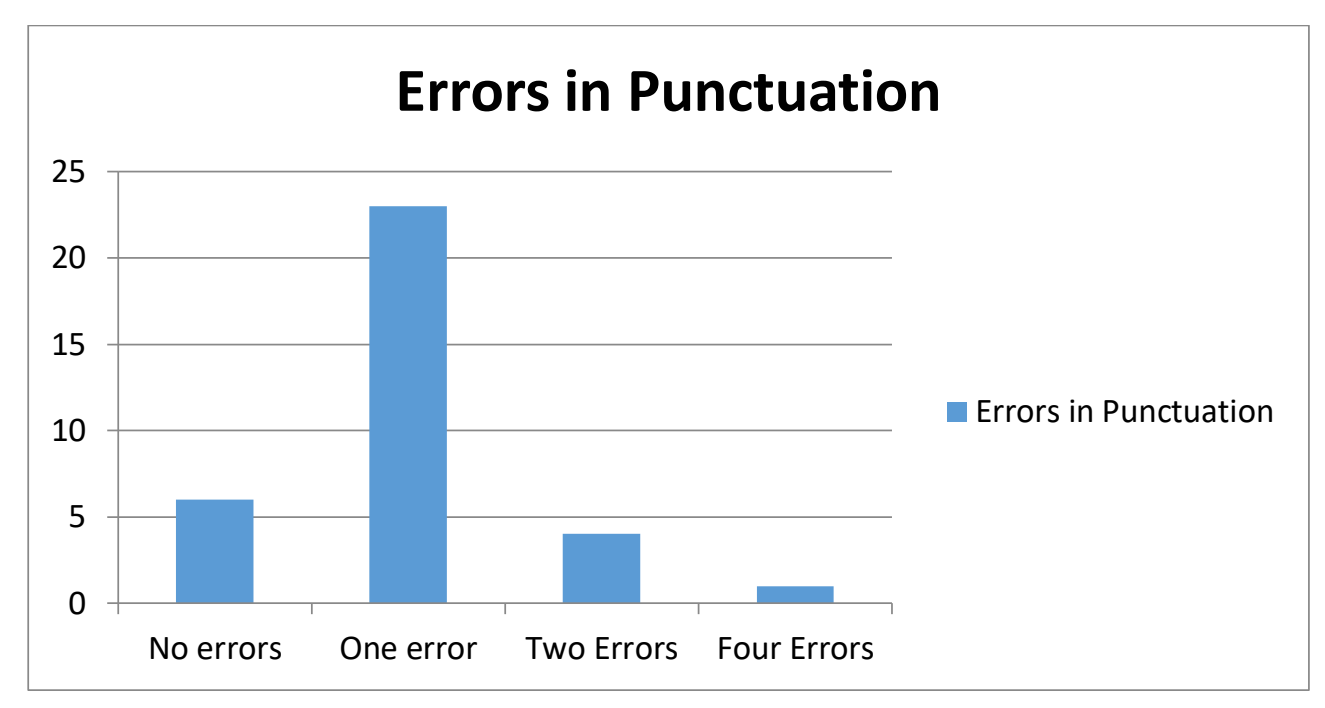

Figure 3. Errors Made in Punctuation

\subsection{The Use of Tamil Word Order (Syntax)}

In this research, essays written by the Tamil school students were carefully marked and analyzed in order to see the influence of Tamil word order in the writing of L2. There are six possible ordering of Subject (S), Object (O) and Verb (V), namely: SOV, SVO, VOS, OVS and OSV.

Tamil language has a free word order (generally) and English word order are relatively strictly organized. It can be inferred that English as SVO word order language and Tamil as an SOV word order language.

Therefore a lot of SOV word order can be seen in the L2 essay writing of Tamil school students. From the Table 1 seen above we can conclude that out of the 35 essays marked, 25 essays had SOV word order. 19 (54\%) students made one error, 6 (17\%) students made two errors and ten (29\%) students made no errors, in their writings. By and large, $71 \%$ of the respondents were influenced by L1 word order.

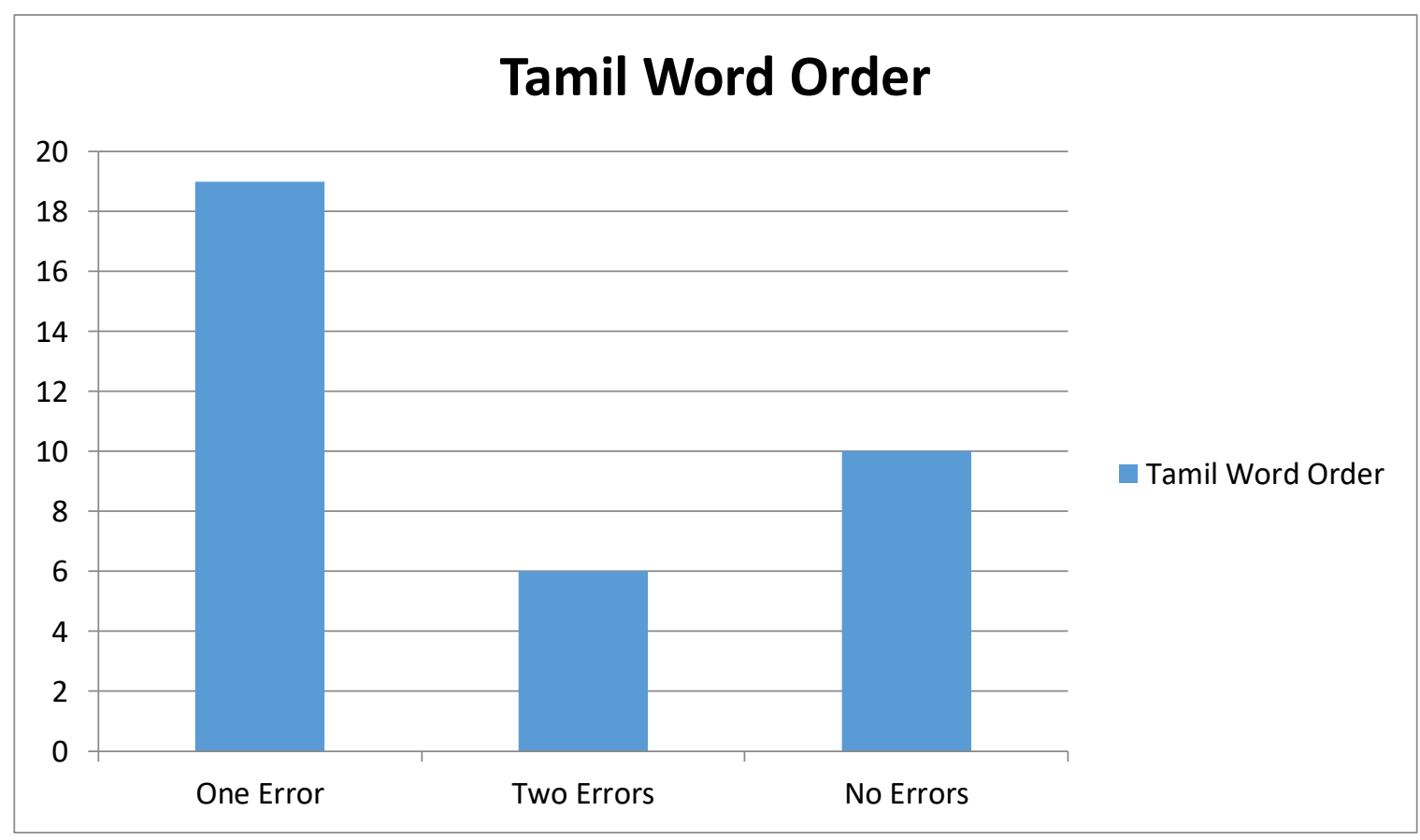

Figure 4. The Use of Tamil Word Order 


\section{The Use of Malay Spelling in the Writing}

\section{of $\mathrm{L} 2$}

As shown in Figure 5, this category was the second highest in the analysis of the essays as many students have been found to have used the Malay (Bahasa Melayu) spelling in their L2 writing. A total of 49 errors were identified in the 35 essays marked. As seen in Table 1, 29 (83\%) respondent used the Malay language spelling in their English language writings. As seen in Table 1, 13 (37\%) students used the Malay spelling once, 12 (34\%) students used the Malay spelling twice, 4 (12\%) used the Malay spelling thrice in their essay writing. Anyhow, $6(17 \%)$ did not use any such spellings in their writings.

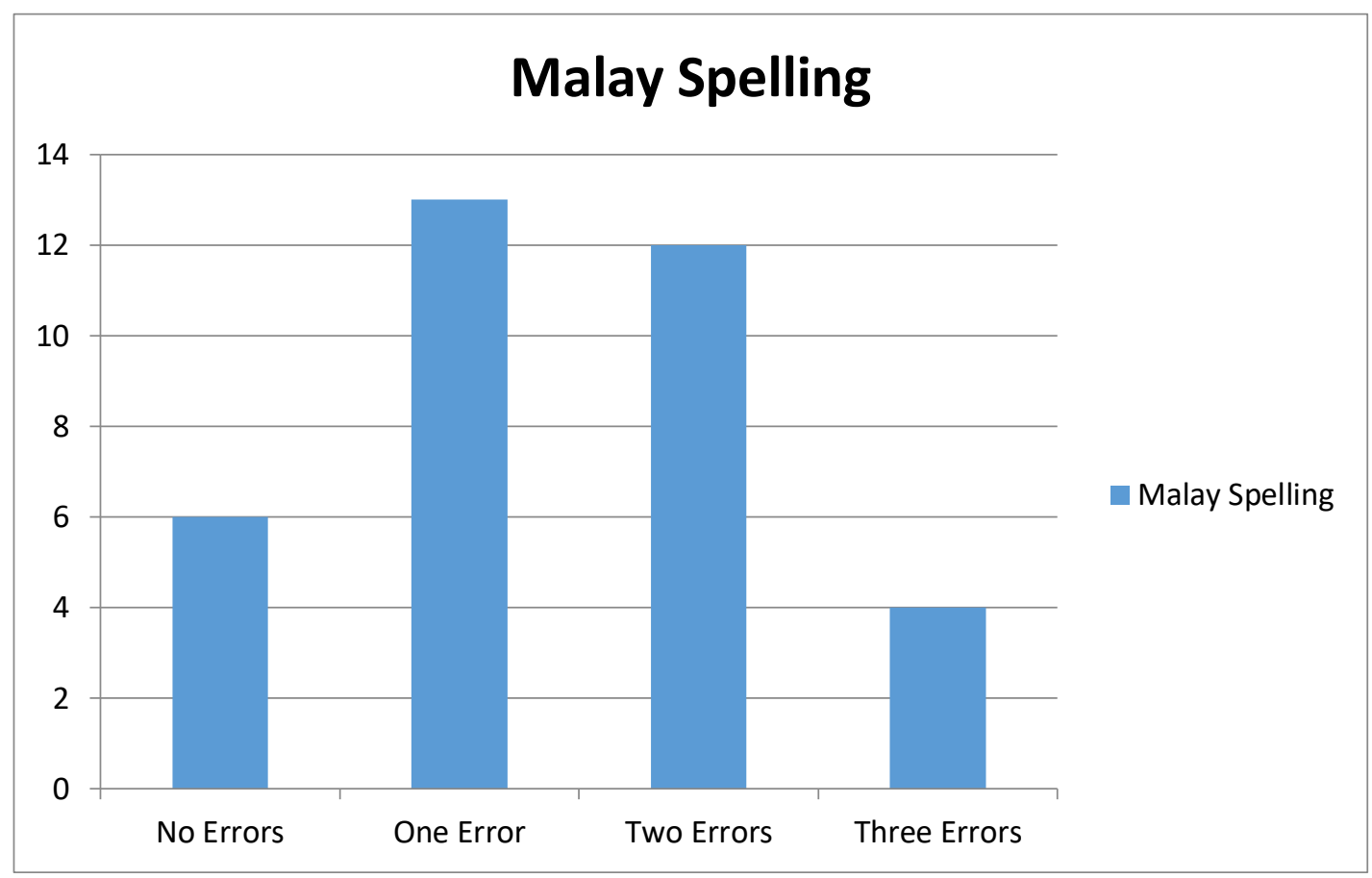

Figure 5. Number of Malay (BM) Spelling Used

\section{Conclusion of Data Analysis}

Based on the data collected from the essays and interviews, it is possible to draw up the following conclusions about the influence of L1 grammatical rules in the writing of $\mathrm{L} 2$ :

1. The linguistic items such as syntactical rulings, capitalization, the use of Malay spelling and failure to use proper punctuation are influenced by the L1 in the writing of L2 among the Tamil school students.

2. The kind of transfer that dominates the influence is the 'Negative Transfer' whereby the grammatical rules of L1 that are not found in L2 are used wrongly in the writing of L2.

3. Students of Tamil schools should be exposed to some kind of contrastive studies in order to help them understand the differences between L1 and L2.

4. When the limited L2 vocabulary command is exhausted the students have the tendency to use Bahasa Melayu (BM) as an alternative in their writing of L2.

5. Students in the Tamil schools should be directly or indirectly taught about the differences of the linguistic items (some, if not all) between the L1 and L2.

6. The research results clearly show that there is no evidence of positive transfer from the L1 in the writing of L2 among the Tamil school students.

\section{Conclusion}

The most prominent linguistic interference identified in this study was incorrect word order. Based on the data this was caused due to the fact 
that English language has the word order of Subject-Verb-Object (SVO) whereas Tamil language has a word order system of SubjectObject-Verb (SVO). The differences in the word order between these two systems has actually caused the negative transfer, whereby students use the L1 word order system in the writing of L2.

The most prominent linguistic interference identified in this study was incorrect word order. Based on the data this was caused due to the fact that English language has the word order of Subject-Verb-Object (SVO) whereas Tamil language has a word order system of SubjectObject-Verb (SVO). The differences in the word order between these two systems has actually caused the negative transfer, whereby students use the L1 word order system in the writing of L2.

Some of the examples taken from students writing to show sentence structure interferences:

She teaches for us English. (அவள் எங்கழுக்கு ஆங்கிலம் கற்பிக்கிறாள்.) ......is actually a direct word order from L1 (Tamil) The classroom in blue colour. (வகுப்பறை நீல நிரதில் உள்ளது.)

is actually a direct word order from L1 (Tamil)

The interview with L2 teacher supports this kind of interferences as they agreed that they have to use their own methodology to advise the students not to construct sentences that are in L1 word order.

"Sometimes, because we know Tamil, we understand the students' problem in writing such sentences. We usually teach them in our own way on the differences between Tamil and English syntax."

The data obtained to answer research questions one and two clearly indicated that there was a strong negative transfer taking place in term of L1 (Tamil) versus L2 (English) in the writing of Tamil school students. The findings are also in consistent with previous studies done by Erdocia and Laka (2018) and Mohideen H (1996).

Teachers who have been interviewed also agreed that L2 learners in Tamil schools are facing interferences from mother tongue and of late the interference from the national language, Bahasa
Melayu is also quite prominent. As what was said in the interview by the $\mathrm{L} 2$ teacher:

Teacher A: U did notice that..... (sighs). I must say that the current challenge in language learning as I encounter is the influence of other languages in English learning. Pupils of this generation are exposed to the use of Malay language, Tamil language and English language in same ratio. They have some confusions on the vocabularies from Tamil to English, Malay to English and Malay to Tamil words. Some English high frequency words are not being translated often in Tamil and Malay language. For examples, computer - komputer (Malay), bus - bas (Malay), cake - Kek (Malay) and so on. These words are being uttered in daily lives when they don't know or may be don't remember the vocabulary in their language translation. Hence, pupils tend to think that these words are common words in the three languages. They use Malay spelling in English and English spelling in Malay essay writings too. There were a few cases in my school where some pupils used English words widely when they write essays in Malay language and vice versa. In order to attain the solution, the Language Panels and English Club is preparing a vocabulary list which gives a clear picture of the vocabulary differences among these three languages.

This is another linguistic phenomena that teachers should look into as there are other inter language issues in vernacular schools now. As vernacular school students are giving equal effort to master the national language, the interference of the Malay language in L2 writing of Tamil school students is slowly but steadily overtaking the influence of mother tongue in L2 writing. Although the literature says that being multilingual helps the learning of a new language, interference of other language should also be taken care by L2 teachers

\section{Personal Insights and Implications of the} Findings

Generally, the study explicitly showed that there was a great influence of mother tongue and the Malay language in the writing of Tamil school students. Therefore students of Tamil schools are 
in a great dilemma of understanding the differences of grammar and syntax in other languages learned. Students in a Tamil school have to learn three languages, and it is better to offer equal teaching hours for all the languages learned.

The findings of this research have clearly revealed that mother tongue has negatively influenced students' written output and this phenomenon has affected the English language achievement of Tamil school students, especially the year Four students. Other factors like insufficient exposure to good models of language use, insufficient reference books, the use of wrong language learning strategies, language spoken at home and inadequate opportunities for professional growth and development of English language teachers. By and large, students' performance and proficiency in the English language in Tamil schools has declined. It has been suggested by language experts in Malaysia that students in vernacular schools in Malaysia should be given equal learning time for all the three language taught in vernacular schools. It is hoped that this study would contribute to the understanding of Tamil school pupils' acquisition of English as an L2 and efforts will be made to upgrade their English language proficiency to prepare them for secondary education which includes more learning hours in English.

This study concludes that the approach adopted by the present study may not be theoretically innovative but the findings, if analyzed carefully, may contribute to the teaching professionals, especially those who are teaching English in a vernacular school. Designers of English syllabus for Tamil schools should identify these issues and change the language learning strategies accordingly.

\section{References}

[1] Alkhateeb, A. (2018). Dynamic transfer and relations between first language (L1) proficiency and second language (L2) writing skills performance. Arab World English Journal (AWEJ) Volume, 9. DOI: https://dx.doi.org/10.24093/awej/vo19no4. $\underline{24}$
[2] Dewi, R., Utami, P. T., \& Hasanah, N. (2019, August). The Influence of L1 Phonological and Orthographic System in L2 Pronunciation: a Study of Brebes Javanese Learners of English. In Fifth Prasasti International Seminar on Linguistics (PRASASTI 2019). Atlantis Press. https://dx.doi.org/10.2991/prasasti$\underline{19.2019 .39}$

[3] Ellis, R. (1997). SLA Research and Language Teaching. Oxford University Press, 198 Madison Avenue,

[4] Erdocia, K., \& Laka, I. (2018). Negative transfer effects on L2 word order processing. Frontiers in psychology, 9, 337.

https://doi.org/10.3389/fpsyg.2018.00337

[5] Ali, H. M. B. M. (1996). Error Analysis. Contribut-ory Factors to Students' Errors, with Special Reference to Errors in Written English. The English Teacher. Vol. 1, xxv. October.

[6] Murakami, A., \& Alexopoulou, T. (2016). L1 influence on the acquisition order of English grammatical morphemes: A learner corpus study. Studies in Second Language Acquisition, 38(3), 365-401. https://doi.org/10.1017/S0272263115000 $\underline{352}$ 